\title{
Assess The Effect of Resistance Training Compared To a Weight Loss Diet Program, on Body Composition, Insulin Sensitivity and Cardio-Vascular Risk Factors In Obese Adolescents.
}

\author{
Abdessalem koubaa ${ }^{1,2}$, Hajer trabelsi ${ }^{2}$, Nizar Tounsi ${ }^{2}$, \\ Saber Nouira ${ }^{2}$, Liwa masmoudi ${ }^{1,2}$, Zouheir Sahnoun ${ }^{1}$, Ahmed Hakim ${ }^{1}$. \\ ${ }^{1}$ Laboratory of Pharmacology, Faculty of Medicine of Sfax, University Sfax, Tunisia \\ ${ }^{2}$ Higher Institute of Sport and Physical Education of Sfax (Tunisia)
}

\begin{abstract}
Purpose: To evaluate the effect of a Resistance training program (BT) versus weight loss diet (DR) on body composition, insulin sensitivity and cardiovascular risk factors in obese adolescents. Methods: Thirty obese adolescents with a BMI above the 97th percentile participated in a training program and diet for 12 weeks. They were randomized into two groups: a diet group $(D R, n=16)$ with a caloric restriction of $500 \mathrm{kcal} /$ day and Strength training group $(B T, n=14)$ for all major muscle groups, three sessions / week with an intensity of 50-80\% (1.RM) for 3 months. Anthropometric and biochemical measurements were performed for all of our subjects before and after the intervention program of 12 weeks. Results: Significant variations of body composition parameters were observed in both groups. The decrease of BMI, body weight, fat mass and (WC) for the group (DR) was more important than the group $(B T)(p<0.01$ and $p<0.05$ respectively). Strength training significantly increases the sensitivity to insulin (HOMA-IR of group (BT), was $4.53 \pm 1.2$ before and $3.47 \pm 1.4$ after the training program $(p<0.05)$ ), while there was no significant change for the group (DR). 12 weeks of strength training, improves the plasma concentrations of TG and HDL-C the LDL-C/HDL-C reports, $T C / H D L-C$ and HDL-C / TG ( $p<0.05)$. The diet of weight loss induced a significant decrease only for the TC and LDL-C. $(4,46 \pm 0.24$ before to $4.15 \pm 0.37$ after and $2.68 \pm 0.18$ before to $2.42 \pm 0.14$ after $(p<0.05)$ respectively). Conclusion: Strength training improves much more the sensitivity to insulin and cardiovascular risk factors than weight loss diet program. The latter is more effective for weight loss, BMI and body fat in obese adolescent boys.
\end{abstract}

Keywords - Obese adolescents, Strength training, diet, lipid, body composition, Insulin resistance.

\section{INTRODUCTION}

Obesity is viewed as a major public health problem whose prevalence is constantly increasing worldwide [1]. This results in obese children and adolescents, a greater increase in cardiovascular disease risk factors such as blood pressure, metabolic dysfunction and insulin resistance [2]. This represents a main determinism of metabolic syndrome observed in a large number of adolescents [3].

In adolescents, a significant relationship between abdominal fat and cardiovascular disease risk factors was found [4]. Generally, overweight and obesity are always the result of an imbalance between energy intake and expenditure, thus leading to excessive storage of fat in adipose tissue. This is a major endocrine organ, producing a variety of regulatory factors energy metabolism and insulin sensitivity [5].

However, it is known that the mobility gradual decrease due to obesity is a major cause of frailty, disability and muscle mass loss and strength. This results in increased difficulty in every day life activities such as walking, climbing stairs, carrying small loads, etc... Obese individuals are at increased risk with reduced physical activity

Skeletal muscle is the most important regulator of lipid oxidation and can have a positive effect on the fat balance. Malfunction of lipid metabolism in the muscle was observed in obese subjects both at rest and during exercise [6]. It is well accepted that aerobic exercise has long-term positive effects on tissue sensitivity to insulin [7-8] and the blood lipid transport [9]. The insulin sensitivity is more important than the decrease, in plasma cholesterol, low density lipoprotein-cholesterol (LDL-C) and apolipoprotein B, is considerable [10].

Although regular physical activity provides substantial health benefits in obese adolescents, we do not know what exercise mode is more beneficial to reduce comorbidities associated with obesity among adolescents. It has been shown that aerobic exercise for 60 minutes three times a week improves levels of LDL cholesterol and triglycerides in obese children [11], reduces abdominal fat and improves blood sugar and insulin resistance [12-13]. Also, Strength training could reduce visceral adipose tissue. The Amercian College of Sports Medicine then recommends regular practice of progressive weight training for people with type 2 diabetes.

The Strength can be an effective strategy to increase functional independence and to decrease the prevalence of many diseases [14]. In this context, it has been shown that three to four sessions per week of 
progressive Strength training, increases both muscle mass and strength [14] and improves glycemic control in adults [15-16].

Therefore, we conducted a randomized controlled study to examine and assess the effect of 12 weeks of Bodybuilding Training compared to a weight loss diet program, on body composition, insulin sensitivity and cardiovascular risk factors on obese boys adolescents. We hypothesize that, among young people, resistance exercise is associated with reduced body fat and improved insulin sensitivity as well as improvements in risk factors related to obesity.

\section{Methods}

\section{1: Participants}

Thirty adolescents participated in this study, which was supported and funded by the Ministry of Scientific Research, Technology and Skills Development of the Republic of Tunisia. The adolescent are from two preparatory schools (Mustapha Sellami and Habib Chaabouni). They were selected for this study at random. After explaining our protocol, a written authorization was signed by the parents, as required by the ethics committee in effect in Tunisia. A certificate of fitness has been established for each subject by our medical team.

According to body mass index (BMI $=$ weight.taille-2, $\mathrm{kg} . \mathrm{m}-2$ ), overweight or obesity were determined. We considered obese, all adolescents with a BMI superior to the $97^{\text {th }}$ percentile of reference curves [17]. The subjects were divided into two groups by a draw. The first group (WL) undergoes only the alimentary Correction. The second group (BB) participates in Strength training program.

\section{2: Body composition}

Mass $(\mathrm{Kg})$ of the subjects was measured with a calibrated electronic scale, standing height with stadiometer, and waist circumference $(\mathrm{cm})$ with a tape. BMI was calculated for each subject using the following formula: weight/ Size2 (kg.m-2).Body fat (\%) was estimated from four skinfolds (supra-iliac, biceps, triceps and subscapularis) according to Durnin and Womersley formula [18]. This fat is used to calculate the Lean Mass (LM) by the formula of Hallynck et al, [19].

$\mathrm{MM}=(1,10 *$ weight $(\mathrm{kg}))-128 *\left[\right.$ weight $\left.^{2} /(100 * \text { height })^{2}\right]$

\section{3: Blood collection and biochemistry}

Venous blood samples (ante-cubital vein) were performed in dry tubes under basal conditions ( $8 \mathrm{am}$ ). After centrifugation, the sera were frozen at $-80^{\circ} \mathrm{C}$ until analysis. Total cholesterol (TC), triglycerides (TG), high-density lipoprotein cholesterol (HDL-C), and glucose levels were measured in all subjects before and after programs after 12 hours of fast using standardized techniques described by Wegge JK [20]. Low-density lipoprotein cholesterol (LDL-C) was calculated as described by the Friedewald formula [21].

The insulin plasma concentration was determined by IRMA (Immunotech, France).

The degree of insulin resistance was estimated using a model of insulin resistance homeostasis (HOMA-IR), and is calculated using the following formula:

[Basal plasma concentration of insulin $(\mu \mathrm{U} . \mathrm{ml}-1) \times$ basal plasma concentration of glucose] / 22.5.

To differentiate between normal sensitivity and altered sensitivity to insulin, HOMA-IR values should be between 2.5 and 4.0 based on those suggested by a previous study Péronnet F; Masssicote D. [22].The definition of metabolic syndrome was made according to the criteria of the World Health Organization [23].

\section{4: Dietary restriction}

Dietary restriction was comprehensive and it is based on nutritional deficiencies recorded during the implementation of the nutrition survey. We opted for this method because it has been suggested through the literature, that severe dietary restriction may have positive short-term effects, but also generates a spectacular recovery of weight in the medium and long term.

During dietary correction sessions, several educational and audiovisual media (round tables, computer presentation, etc. ....) were used to inform adolescent and their parents about the balanced nutrition importance for health. In addition, these sessions are based on the amount of recommended dietary intake for this age category as well as on the proportion of macronutrients (55\% carbohydrate, $30 \%$ fat and $15 \%$ protein) that must have their diet. They also aimed to reduce - $500 \mathrm{kcal} . \mathrm{j}$-1 of its initial energy intakes for. The foods were chosen according to the dietary habits of the subject. 


\section{5: Exercice testing}

The maximum strength of each muscle group concerned was examined, using a maximum concentric repetition (1-RM) [24]. The force was defined as the maximum weight that could be lifted or pulled with a limb full movement. In all tests, the subjects were verbally encouraged to perform to do their best and as quickly as possible.

\section{6: Training program}

The training period lasted 3 months and is designed to increase the lipid oxidation rate in our subjects.

This resistance training type was chosen because the performance of every day life activities requires both strength and muscle power. Thus, it has been reported as an effective strategy to minimize the declines related to obesity in muscle mass, maximal strength and muscle output power in obese subjects [25]. Thus, three workouts per week, for 3 months, lasting $60 \mathrm{~min}$ each were planned, carried out in collaboration with physical education teachers in a gym.

The Strength program included a series of 10 exercises for the majority of muscle groups 3 times / week for $60 \mathrm{~min} / \mathrm{session}$. Each training session consisted of leg press, leg extension, leg curl, pectorals, latissimus dorsi, seated row, biceps and triceps. In addition, a set of exercise push-ups and sit-ups were conducted in each training session.

During the first 6 weeks of the training period, adolescent have achieved 10 to 15 repetitions per set and 3 to 4 sets for each exercise, at 50-70\% of the first repetition maximum (1.RM) with proper lifting techniques.

Over the last six weeks of the training period, loads weight were 70 to $80 \%$ of (1.RM), 5 to 6 repetitions per set and 3 to 5 sets for each exercise. In all training sessions conducted, trainers were present to guide and assist each subject to execution with rhythms and loads of suitable work.

Control subjects were asked to maintain their daily activity (no participation in physical activities).

\section{7: Statistical Analysis}

All statistical tests were performed using STATISTICA Software (StatSoft, France). Analysis of variance (ANOVA) was applied. Fischer LSD post hoc test was performed where appropriate. Differences between Strength training (BT) and weight loss diet (DR) were analyzed using non-paired Student's t-test. A probability level of 0.05 was selected as the criterion for statistical significance. All values are expressed as mean \pm standard deviation (SD).

\section{RESULTS}

In our study, Strength training has promoted significant weight loss, which was observed in group subjects (BT) $(83.6 \pm 12.9 \mathrm{~kg}$ before vs. $81.4 \pm 12.4 \mathrm{~kg}$ after $)$.

A significant reduction $(\mathrm{P}<0.01)$ was observed in the diet group, Indeed, the body weight of the adolescent group (DR) rose from $82.3 \pm 12.4 \mathrm{~kg}$ before to $77.5 \pm 103 \mathrm{~kg}$ after this same period

Table1. Anthropometric characteristics before and after program in DR and BT groups (mean \pm ST).

\begin{tabular}{|lcccc|}
\hline & \multicolumn{2}{c}{ DR $(\mathrm{n}=16)$} & \multicolumn{2}{c|}{ BT $(\mathrm{n}=14)$} \\
Parametres & Before & After & Before & After \\
\hline Weight $(\mathrm{kg})$ & $82,3 \pm 12,4$ & $77,5 \pm 10,3^{* *}$ & $83,6 \pm 12,9$ & $81,4 \pm 12,4^{*}$ \\
\hline BMI $\left(\mathrm{kg} \cdot \mathrm{m}^{-2}\right)$ & $30,94 \pm 3,6$ & $29,14 \pm 3,1^{* *}$ & $31,43 \pm 2,8$ & $30,6 \pm 3,5^{*}$ \\
\hline Fat mass $(\mathrm{kg})$ & $34,3 \pm 5,8$ & $29,4 \pm 6,2^{* *}$ & $34,1 \pm 7,2$ & $32,2 \pm 6,7^{*}$ \\
\hline Fat free mass $(\mathrm{kg})$ & $47,90 \pm 8,1$ & $46,31 \pm 7,6$ & $47,6 \pm 7,1$ & $48,3 \pm 6,9$ \\
\hline \hline waist circumference $(\mathrm{cm})$ & $96,9 \pm 7,4$ & $90,7 \pm 8,8^{* *}$ & $98,1 \pm 10,8$ & $96,2 \pm 12,3$ \\
\hline
\end{tabular}

Legend: DR, dietary restriction; BT, Strength training; BMI, body mass index;

$* \mathrm{p}<0,05 ; * * \mathrm{p}<0,01 ; * * * \mathrm{p}<0,001$ after versus before program

The decrease in body mass index (BMI) in both groups (DR) and (BT) follows the same trend as weight, with values respectively from $30.94 \pm 3.6 \mathrm{~kg} . \mathrm{m}-2$ before to $29,14 \pm 3.1 \mathrm{~kg} . \mathrm{m}-2$ after $(\mathrm{P}<0.01)$ and of $31.43 \pm 2.8 \mathrm{~kg} . \mathrm{m}-2$ before to $30.6 \pm 3.5 \mathrm{~kg} . \mathrm{m}-2$ after the training phase $(\mathrm{P}<0.05)$

Our program also induces a decrease in fat mass in all our subjects. It decreases in the group (DR) from $34.3 \pm 5.8 \mathrm{~kg}$ before to $29.4 \pm 6.2 \mathrm{~kg}$ after 12 weeks of dietary adjustment. The same is observed for the group subjects (BT), in which fat loss in kilograms is less marked than the group subjects (DR) $(-4.9 \mathrm{~kg}$ ( $\mathrm{P}$ $<0.01)$ Vs $-1.9(\mathrm{P}<0.05)$ respectively $)$ 
Compared to the training group (BT), our program of caloric restriction group (DR) induced a significant decrease in waist circumference (WC) $(\mathrm{P}<0.01)$, it decrease from $96.9 \pm 7.4 \mathrm{~cm}$ before to $90.7 \pm 8.8$ $\mathrm{cm}$ after the diet program.

Neither the dietary correction nor the resistance training over a period of 12 weeks could alter lean mass in all our subjects. However, a slight increase of $+0.67 \pm 0.9 \mathrm{~kg}$ of this mass was observed in patients in (BT) $(\mathrm{p}=0.078)$. The values go from $47.6 \pm 7.1 \mathrm{~kg}$ before to $48.3 \pm 6.9 \mathrm{~kg}$ after this period.

The HOMA-IR parameter values in pre and post program are summarized in Table (2). Before our program, glucose basal plasma concentrations and insulin were significantly similar in all our subjects.

Table2. Insulin sensitivity changes of two groups: DR and BT. (mean \pm ST)

\begin{tabular}{|lcccc|}
\hline & \multicolumn{2}{c}{ DR $(\mathbf{n}=\mathbf{1 6})$} & \multicolumn{2}{c|}{ B T $(\mathbf{n = 1 4})$} \\
Parametres & Before & After & Before & After \\
\hline Glucose $\left(\mathrm{mmol}^{-1} \mathrm{I}^{-1}\right)$ & $4,82 \pm 0,17$ & $4,76 \pm 0,11$ & $4,77 \pm 0,14$ & $4,75 \pm 0,19$ \\
\hline Insulin $\left(\mu \mathrm{U} \cdot \mathrm{ml}^{-1}\right)$ & $21,9 \pm 5,8$ & $21,1 \pm 4,7$ & $20,8 \pm 4,6$ & $15,9 \pm 4,1 *$ \\
\hline \hline HOMA-IR & $4,47 \pm 1,6$ & $4,24 \pm 1,5$ & $4,53 \pm 1,2$ & $3,47 \pm 1,4 *$ \\
\hline
\end{tabular}

Legend: HOMA-IR: Homeostasis of insulin resistance; $* \mathrm{p}<0,05 ; * * \mathrm{p}<0,01 ; * * * \mathrm{p}<0,001$ after versus before program.

Compared to the group (DR) Table (2) shows a significant decrease in insulin basal plasma concentrations in subjects of (BT). This is of $-4.9 \pm 1.8 \mathrm{uU} / \mathrm{ml}(\mathrm{p}<0.05)$. The significant decrease in the HOMA-IR values of training group (BT) reflects improved insulin sensitivity. Its value, decreased from $4.53 \pm$ 1.2 before to $3.47 \pm 1.4$ after the training program ( $\mathrm{p}<0.05$ ).

No significant change in glucose basal plasma concentrations in patients of both groups.

Table3. Lipid changes of two groups: DR and BT. (mean \pm ST)

\begin{tabular}{|lcccc|}
\hline & \multicolumn{2}{c}{ DR $(\mathrm{n}=16)$} & \multicolumn{2}{c|}{ B T $(\mathrm{n}=14)$} \\
\hline Parametres & Before & After & Before & After \\
\hline TG (mmol/ $)$ & $1,53 \pm 0,21$ & $1,51 \pm 0,32$ & $1,48 \pm 0,24$ & $1,35 \pm 0,16^{*}$ \\
\hline TC $(\mathrm{mmol} / \mathrm{l})$ & $4,46 \pm 0,24$ & $4,15 \pm 0,37^{*}$ & $4,37 \pm 0,33$ & $4,18 \pm 0,56$ \\
\hline HDL-C (mmol/1) & $1,08 \pm 0,13$ & $1,04 \pm 0,07$ & $1,06 \pm 0,12$ & $1,13 \pm 0,1^{*}$ \\
\hline LDL-C (mmo1/1) & $2,68 \pm 0,18$ & $2,42 \pm 0,14 *$ & $2,63 \pm 0,26$ & $2,43 \pm 0,31$ \\
\hline Ratio LDL-C/HDL-C & $2,48 \pm 0,42$ & $2,32 \pm 0.29$ & $2,48 \pm 0.12$ & $2,15 \pm 0,11^{*}$ \\
\hline Ratio CL/HDL-C & $4,13 \pm 0,21$ & $3,99 \pm 0,28$ & $4,12 \pm 0,35$ & $3,70 \pm 0,32^{*}$ \\
\hline Ratio HDL-C/T G & $0,71 \pm 0,11$ & $0,69 \pm 0,09$ & $0,72 \pm 0,1$ & $0,84 \pm 0,16^{*}$ \\
\hline
\end{tabular}

Legend: HDL-C, height density lipoprotein cholesterol; LDL-C, low density lipoprotein cholesterol; TC, Total cholesterol; TG, triglyceride, ${ }^{*} \mathrm{p}<0,05 ; * * \mathrm{p}<0,01 ; * * * \mathrm{p}<0,001$ after versus before program

As shown in Table 3, after 12 weeks resistance training, the plasma concentrations of TG and HDL-C have been significantly improved. Similarly, we recorded in the same subjects (BT), the LDL-C/HDL-C reports, TC / HDL-C and HDL-C / TG lowered ( $\mathrm{p}<0.05)$.

For group subjects (DR), our dietary restriction program induced a significant decrease for only the TC and LDL-C. The values were respectively $4.46 \pm 0.24$ before to $4.15 \pm 0.37$ after $(\mathrm{p}<0.05)$ and $2.68 \pm 0.18$ before to $2.42 \pm 0.14$ after $(\mathrm{p}<0.05)$.

\section{DISCUSSION}

We examined the effects of 12 weeks of Strength training versus calorie restriction on body composition, abdominal fat, lipid profile and insulin sensitivity in obese sedentary adolescent boys.

It has been shown that weight loss induced by either exercise or diet improves insulin sensitivity [2627]. Our data extend these observations and suggest that Strength exercise without caloric restriction is associated with an improvement of $23.6 \%$ of the insulin sensitivity in the group (BT). Our findings are consistent with the Rice et al conclusions [28].

It has been reported that the insulin sensitivity improvement, is associated with improved skeletal muscle mass [29]. Thus, significant improvements in insulin sensitivity in the Strength group, are likely to be partly explained by a significant increase in skeletal muscle mass. In addition, it was demonstrated, in a recent study, that improved insulin sensitivity after Strength training is the result of muscle mass increase without altering the intrinsic ability of the muscle to respond to the insulin [30]. Finally, muscle mass increase can have a significant effect on glucose tolerance and insulin sensitivity. Similarly, this increase could enhance the 
storage area of glucose available, thus facilitating the release of glucose from the circulation and reduce the amount of insulin required to maintain a glucose normal tolerance [29-31]. Eriksson et al. [32] found that after 3 months of resistance training, improved glycemic control is strongly correlated with the muscle size.

After 12 weeks of Strength training proposed to our subjects, body composition changes were illustrated. They are characterized by a reduction in body weight, BMI and body fat retaining fat free mass. Thus, the average loss of body mass of all of our subjects was $-3.5 \mathrm{~kg}$. Our findings are concomitant with the previous studies results [33-34-35-36]. This loss of body mass is substantially similar to that found by Lazzer et al. [35-36] and higher than that found by [34].

In addition, the body mass loss recorded in our study varies in accordance with the groups. It is important in (DR) compared to those of (BT). The (DR) group lost $-4.8 \pm 2.7 \mathrm{~kg}$, while (BT) lost only $-2.1 \pm 0.8$ $\mathrm{kg}$. Several hypotheses could be advanced to explain this variety of intergroup response. The main finding is that the isolated use of dietary restriction has positive effects on the reduction of the child body weight [37-38]. The decrease in body weight observed in group subjects (DR) is therefore consistent with the progress of this work and therefore could be explained by a reduction in caloric intake.

The results of this study show an unfavorable response of plasma TC and LDL-C to strength training. By cons, adolescents who have undergone the caloric restriction, showed a significant decrease in TC and LDL$\mathrm{C}(\mathrm{p}<0.05)$. These results are consistent with most studies which showed that there is no improvement in lipid profiles after resistance training program [39-40-41]. Indeed, two other studies have concluded that resistance training does not seem to change blood lipid and lipoprotein levels [42-43].Surprisingly, no changes in the lipid profile were found in the (DR) group, even though significant differences were observed in the body mass loss and fat mass. Whereas no clear dose-response relationship between weight loss and lipid modulations could be determined, it seems that testing undergoing weight reduction $>5 \%$ of initial body weight appear to observe the most significant changes of TC concentrations and LDL-C [44]. However, it was the case with our group (BT), in which a decrease of approximately 2, 2\% was not translated to TC an improvement and LDL-C.

Based on these results, it should be deduced that Strength exercise was the main factor responsible for the improvement of the lipid profile in our group (BT). Such finding confirms the results of Fahlman et al. [45] who found that resistance training for 10 weeks, improves the lipid profile of overweight women without concurrent changes in weight or diet.

As for the significant increase of HDL-C in group (BT). This finding is at odds with most results of the literature. Indeed, Durstine et al. [43-46] Hellenius et al. [47] concluded that if there is a weight loss induced by either dietary intervention or exercise, HDL-C rates decreases or does not change.

In our study we showed that dietary restriction alone produces changes in the lipid profile of our subjects. At the end of this intervention, group subjects (DR) lowered its values in TC and LDL-C. By against in group subjects (BT), the Strength training, improves first, the ability to oxidise lipid to exercise and the other hand, it induces a decrease TG and an increase HDL-C. In addition we found an increase of HDL-C/TG report and lipid oxidation rates at maximal exercise and decreased HOMA-IR.

Several studies indicate that obesity is a major risk factor for cardiovascular disease [2]. In humans it was found that, increased values in TC and LDL-C and decreased HDL-C are associated with a high risk of developing atherosclerosis [48]. In addition, a decreased HDL-C concentration is commonly seen as a reflection of insulin resistance [49].

It was also suggested that the TC / HDL reports and LDL / HDL, are more interesting preachers of cardiovascular disease than isolated values of HDL, LDL and TC [50]. The evidence that supports this assumption, derived from the adaptations induced by our program in group subjects (BT), resulting thus in a reduced risk of cardiovascular disease. In these subjects, significant decreases in plasma concentrations of TC, LDL-C, TC / HDL-C, and LDL-C/HDL-C were observed. These were greater than in group subjects (DR).

The main conclusions of this study are that Strength training at an intensity of 50-80\% (1.RM) in obese adolescents, has led to significant improvements in body composition, insulin sensitivity and the factors cardiovascular risks. These observations suggest that three resistance training sessions per week could serve as an effective strategy for the adolescent obesity treatment. It can have a significant practical interest for the optimal design of training programs for obese adolescents.

\section{CONCLUSION}

The main conclusion is that a caloric restriction program or Strength training has resulted in significant reductions in total fat, and risk factors and cardio-respiratory fitness improvement in obese adolescent boys. In addition, resistance exercise has been effective in improving insulin sensitivity, skeletal muscle mass and muscle strength. Our results have important implications for health and provide therapeutic strategies for health care professionals for the childhood obesity treatment and reduce insulin resistance in moderately obese boys. 


\section{Acknowledgements}

The authors would like to thank the subjects involved for their efforts and commitments throughout the study. This study was conducted with the approval of the Research Ethics Committee of the faculty of medicine of Sfax, Tunisia.

\section{Conflict of interests: None}

\section{REFERENCES}

[1]. Ebbeling CB, Pawlak DB, Ludwig DS. Childhood obesity: public health crisis, common sense cure. Lancet 2002; 360:473-482.

[2]. Steinberger J, Daniels SR. Obesity, insulin resistance, diabetes and cardiovascular risk in children. Circulation 2003; 107:1448-53.

[3]. Weiss R, Dziura J, Burgert TS, Tamborlane WV, Taksali SE, Yeckel CW, et al. Obesity and the metabolic syndrome in children and adolescents. N Engl J Med 2004; 350:236-274.

[4]. Maffeis C, Corciulo N, Livieri C, et al. Waist circumference as a predictor of cardiovascular and metabolic risk factors in obese girls. Eur J Clin Nutr 2003;57:566-72.

[5]. Kershaw, E.E and Filier. Adipose tissu as an endocrine organ. J Clin Endocrinol Metab 2004; 89:2548-56

[6]. Goodpaster BH, Wolfe RR and Kelley DE. Effects of obesity on substrate utilization during exercise. Obes Res 2002; 10:575-84.

[7]. Kang HS, Gutin B, Barbeau P, et al. Physical training improves insulin resistance syndrome markers in obese adolescents. Med Sci Sports Exerc 2002; 34:1920-7.

[8]. Fenicchia LM, Kanaley JA, Azevedo JL, Miller CS, Weinstock RS, Carhart RL, Ploutz-Snyder LL: Influence of resistance exercise training on glucose control in women with type 2 diabetes. Metabolism 53:284-289, 2004.

[9]. Haskell WL (1984) Exercise-induced changes in plasma lipids and lipoproteins. Prev Med 13, 23-36.

[10]. Després JP, Moorjani S, Tremblay A, Poehlman ET, Lupien P J, Nadeau A, Bouchard C Heredity and changes in plasma lipids and lipoproteins after short-term exercise training in men. Arteriosclerosis.1988; 8: 402-9.

[11]. Escalante Y, Saavedra JM, García-Hermoso A, Domínguez AM. Improvement of the lipid profile with exercise in obese children: a systematic review. Prev Med 2012; 54:293-301.

[12]. Irwin ML, Yasui Y, Ulrich CM, et al. Effect of exercise on total and intra-abdominal body fat in postmenopausal women: a randomized controlled trial. JAMA 2003; 289:323-330.

[13]. Poehlman ET, Dvorak RV, DeNino WF, Brochu M, Ades PA. Effects of resistance training and endurance training on insulin sensitivity in nonobese, young women: a controlled randomized trial. J Clin Endocrinol Metab 2000; 85:2463-2468.

[14]. American College of Sports Medicine: Exercise and physical activity for older adults: position stand. Med Sci Sports Exerc 30:992-1008, 1998

[15]. Castaneda C, Layne JE, Munoz-Orians L, Gordon PL, Walsmith J, Foldvari M, Roubenoff R, Tucker KL, Nelson ME: A randomized controlled trial of resistance exercise training to improve glycemic control in older adults with type 2 diabetes. Diabetes Care 25:2335-2341, 2002

[16]. Cuff DJ, Meneilly GS, Martin A, Ignaszewski A, Tildesley HD, Frohlich JJ: Effective exercise modality to reduce insulin resistance in women with type 2 diabetes. Diabetes Care 26:2977-2982, 2003

[17]. Rolland-Cachera MF, Cole TJ, Sempé M, Tichet J, Rossignol C, Charraud, A. Body mass index variations: centiles from birth to 87 yearth. Eur J Clin Nutr 1991; 45: 13-21.

[18]. Durnin JVGA, Womersley J. Body fat assessed from total body density and its estimation from skinfold thickness: measurements on 481 men and women aged from 16 to 72 years. Br J Nutrition. 1974; 32: 77- 97.

[19]. Hallynck TH; Soep HH et al. should clearance be normalised to body surface or to lean body mass? Br J Clin Pharmacol.1981; 11; 523-526.

[20]. Wegge JK, Roberts CK, Ngo TH, et al. Effect of diet and exercise intervention on inflammatory and adhesion molecules in postmenopausal women on hormone replacement therapy and at risk for coronary artery disease. Metabolism 2004; 53:77-81.

[21]. Friedewald WT, Levy RI, Fredrickson DS. Estimation of the concentration of low-density lipoprotein cholesterol in plasma, without use of the preparative ultracentrifuge. Clin Chem 1972; 18:499-502.

[22]. Péronnet F, Massicotte D. Table of non protein respiratory quotient: an update. Can J Sports Sci 1991; 16:23-29.

[23]. Mc Gilvery RW, Goldstein GW. Biochemistry: A function approach. Philadelphia: saunders 1983; 810-976.

[24]. Cuff DJ, Meneilly GS, Martin A, Ignaszewski A, Tildesley HD, Frohlich JJ: Effective exercise modality to reduce insulin resistance in women with type 2 diabetes. Diabetes Care 26:2977-2982, 2003

[25]. Izquierdo M, Häkkinen K, Ibáñez J, Garrués M, Antón A, Zúñiga A, Larrión JL, Gorostiaga EM: Effects of strength training on muscle power and serum hormones in middle-aged and older men. J Appl Physiol 90:1497-1507, 2001.

[26]. Ross R, Dagnone D, Jones PJ, et al. Reduction in obesity and related comorbid conditions after diet-induced weight loss or exercise-induced weight loss in men. A randomized, controlled trial.Ann Intern Med 2000; 133:92-103.

[27]. Goodpaster BH, Kelley DE, Wing RR, Meier A, Thaete FL. Effects of weight loss on regional fat distribution and insulin sensitivity in obesity. Diabetes 1999;48: 839-847.

[28]. Rice B, Janssen I, Hudson R, Ross R: Effects of aerobic or resistance exercise and/or diet on glucose tolerance and plasma insulin levels in obese men. Diabetes Care 22:684-691, 1999.

[29]. Miller WJ, Sherman WM, Ivy JL. Effect of strength training on glucose tolerance and post-glucose insulin response. Med Sci Sports Exerc 1984;16: 539-543.

[30]. Poehlman ET, Dvorak RV, DeNino WF, Brochu M, Ades PA: Effects of resistance training and endurance training on insulin sensitivity in nonobese young women: a controlled randomized trial. J Clin Endocrinol Metab 85:2463-2468, 2000.

[31]. Boulé NG, Haddad E, Kenny GP, Wells GA, Sigal RJ: Effects of exercise on glycemic control and body mass in type 2 diabetes mellitus. JAMA; 286:1218-1227, 2001.

[32]. Eriksson J, Taimela S, Eriksson K, Parviainen S, Peltonen J, Kujala U: Resistance training in the treatment of non-insulindependent diabetes. Int J Sports Med 18:242-246, 1997.

[33]. Dumortier M, Brandou F, Perez-Martin A, Fedou C, Mercier J, Brun JF. Low intensity endurance exercise targeted for lipid oxidation improves body composition and insulin sensitivity in patients with the metabolic syndrome. Diabetes Metab 2003; 29: 509-518.

[34]. Brandou F, Dumortier M, Garandeau P, Mercier J, Brun JF. Effects of two-month rehabilitation program on substrate utilization during exercise in obese adolescents. Diabetes Metab 2003; 29: 20-27

[35]. Lazzer S, Boirie Y, Montaurier C, Vernet J, Meyer M, Vermorel M. A weight reduction program preserves fat-free mass but not metabolic rate in obese adolescents. Obes Res 2004; 12: 233-240. 
[36]. Lazzer S, Boirie Y, Poissonnier C, Petit I, Duche P, Taillardat M, Meyer M, Vermorel M. Longitudinal changes in activity patterns, physical capacities, energy expenditure, and body composition in severely obese adolescents during a multidisciplinary weight-reduction program. Int J of Obesity 2005; 29: 37-46.

[37]. Foster GD, Wyatt HR, Hill JO, et al. A randomized trial of a low-carbohydrate diet for obesity. N Engl J Med 2003; 348: 20822090.

[38]. Boden G, Sargrad K, Homko C, Mozzoli M, Stein TP. Effect of a low-carbohydrate diet on appetite, blood glucose levels, and insulin resistance in obese patients with type 2 diabetes. Ann Intern Med 2005; 142: 403-411.

[39]. Treuth MS, Hunter GR, Kekes-Szabo T et al. Reduction in intra-abdominal adipose tissue after strength training in older women. J Appl Physiol 1995; 78: 1425-1431.

[40]. Kokkinos PF, Hurley BF, Vaccaro P et al. Effects of low- and high-repetition resistive training on lipoprotein-lipid profiles. Med Sci Sports Exerc 1988; 20: 50-54.

[41]. Blumenthal JA, Matthews K. Fredrikson M et al. Effects of exercise training on cardiovascular function and plasma lipid, lipoprotein, and apolipoprotein concentrations in premenopausal and postmenopausal women. Arterioscler Thromb 1991; 11:912917.

[42]. Braith RW, Stewart KJ. Resistance exercise training: its role in the prevention of cardiovascular disease. Circulation 2006; 113:2642-2650.

[43]. Durstine JL, Grandjean PW, Davis PG et al. Blood lipid and lipoprotein adaptations to exercise: a quantitative analysis. Sports Med2001; 31: 1033-1062.

[44]. Varady KA, Jones PJ. Combination diet and exercise interventions for the treatment of dyslipidemia: an effective preliminary strategy to lower cholesterol levels? J Nutr 2005; 135: 1829-1835.

[45]. Fahlman MM, Boardley D, Lambert CP, Flynn MG. Effects of endurance training and resistance training on plasma lipoprotein profiles in elderly women. J Gerontol A Biol Sci Med Sci 2002; 57: B54-B60.

[46]. Schneider JG, von Eynatten M, Schiekofer S, Nawroth PP, Dugi KA. Low plasma adiponectin levels are associated with increased hepatic lipase activity in vivo. Diabetes Care 2005; 28: 2181-2186.

[47]. Hellénius ML, Krakau I, de Faire U. Favourable long-term effects from advice on diet and exercise given to healthy men with raised cardiovascular risk factors. Nutr Metab Cardiovasc Dis 1997; 7:293-300.

[48]. Koro CE, Bowlin SJ, Stump TE, Sprecher DL, Tierney WM. The independent correlation between high-density lipoprotein cholesterol and subsequent major adverse coronary events. Am Heart J 2006; 151:755-6.

[49]. Karhapaa P, Malkki M, Laakso M. Isolated low HDL cholesterol. An insulin-resistant state. Diabetes 1994; $43: 411-7$.

[50]. Natarajan S, Glick H, Criqui M, et al. Cholesterol measures to identify and treat individuals at risk for coronary heart disease. Am J Prev Med 2003; 25: 50-7. 